\title{
Sample Preparation of a Novel Titanium-Aluminium Composite for EBSD Analysis
}

\author{
D.J. Attard*, R. Wuhrer **, P.G. Huggett*** and K. Moran **** \\ * Australian Nuclear Science and Technology Organisation, Institute of Materials and Engineering \\ Science, PMB 1, Menai, NSW 2234. \\ ${ }^{* *}$ Microstructural Analysis Unit and *** Department of Chemistry, Materials and Forensic Sciences, \\ University of Technology Sydney, PO BOX 123, Broadway NSW 2007. \\ ***** Moran Scientific Pty Ltd, P.O. Box 651Goulburn NSW 2580
}

A titanium-aluminium composite (TAC) has been produced using a novel vacuum cast process $[1,2]$ that has potential in biomedical and industrial plant applications. The overall aims of this investigation are to develop an understanding of the phase transformations and alloy segregation at the interface between the bonded titanium-aluminium composite. With soft alloys, it is important to polish the surface without distortion of the grain shape. Initially, the samples were prepared using standard metallographic techniques, but difficulties preparing the composite material were experienced. A preparation method was developed for the bonded titanium-aluminium composite material that produced damage-free samples. These were characterised using imaging, X-ray mapping (XRM) and Electron Back Scatter Diffraction (EBSD) in a Scanning Electron Microscope (SEM).

Preparation methods for titanium and aluminium alloys, similar to those being investigated, are available from suppliers of metallographic consumables, and produce an excellent surface finish that reveals the true material structure $[3,4]$. However, these methods were unsuitable for preparing the TAC, as they produced coarse scratching and abrasive particles embedded in the titanium alloy. These preparation artefacts were clearly identified by optical microscopy, and were eliminated with careful selection of the grinding/polishing media and using chemical-mechanical polishing techniques. The modified method produced a scratch-free surface, and although grain relief was observed when viewed with Differential Interference Contrast (DIC) microscopy, all of the grains were in focus suggesting that the height differences were extremely small.

Secondary Electron Imaging (Figure 1a) shows a scratch-free surface and EBSD produced pattern quality indexes above $90 \%$ in the titanium alloy, indicating that the preparation method used was effective in minimising sub-surface damage. Despite good quality EBSD patterns in the aluminium and diffusion zone, they were poorly indexed. The complexity of the microstructure and the chemical composition shown in the psuedo-colour X-ray map of the diffusion zone in Figure $1 \mathrm{~b}$ indicate why. 


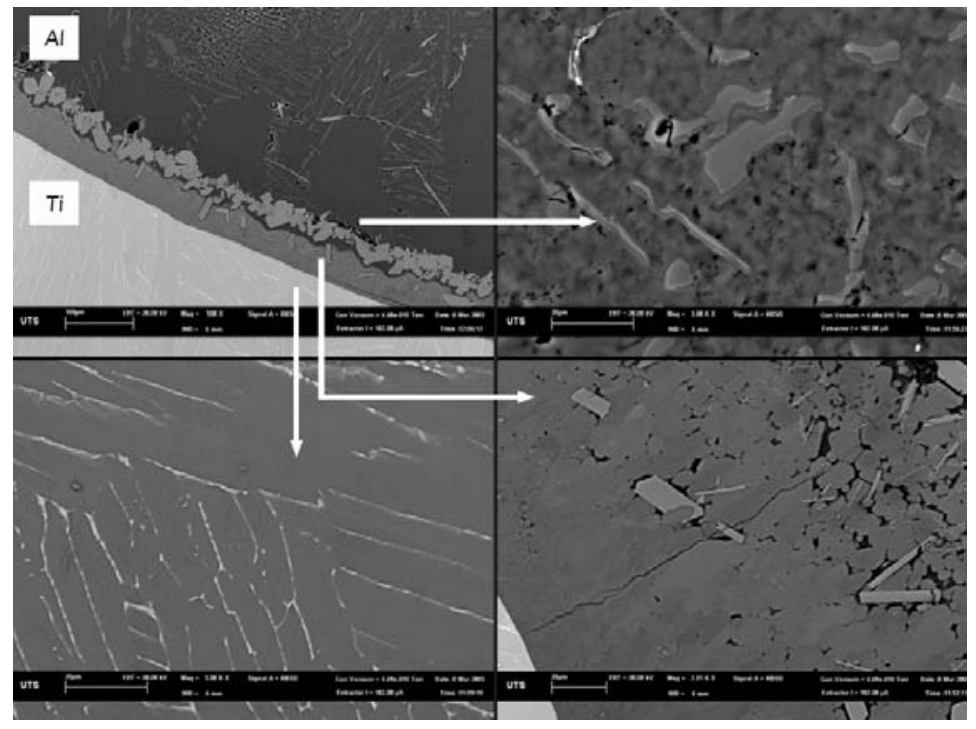

a.

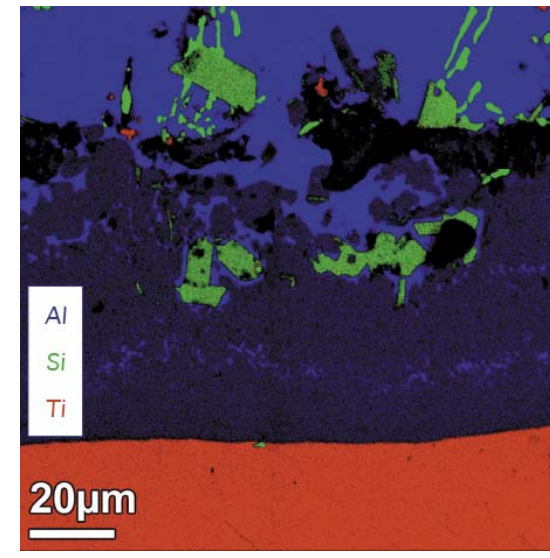

b.

Figure 1: a. SEM images taken of the titanium-aluminium composite using a Zeiss Supra 55VP with in-lens detector and b. Pseudo colour x-ray map of the diffusion zone between the Titanium and aluminium alloys.

Further work is planned to optimise the EBSD parameters for each region in the TAC. Increasing the band detection, reflector and Hough transform resolution parameters may be required to discriminate between the phases present. Furthermore, it may be necessary to map each of these regions separately due to the different crystal systems (HCP) in titanium, cubic in aluminium, unknown in the diffusion zone). EBSD in combination with XRM should then provide an understanding of the phase transformation and alloy segregation behaviour between the titanium and aluminium alloys during this novel vacuum casting process.

\section{References}

[1] P. Huggett, R. Wuhrer, B. Ben-Nissan and K. Moran, "A novel metallurgical bonding process and microstructural analysis of ferrous alloy composites", Materials Forum, Volume 29, Edited by J.F. Nie and M. Barnett, IMEA (2005) 83-88.

[2] R. Wuhrer, K. Moran, P. Huggett, M.R. Phillips and B. Ben-Nissan, "EBSD and XRM of Phases in Vacuum Cast Composite Alloys", Microsc Microanal 11(Suppl 2), 2005.

[3] L.E. Samuels, "Metallographic Polishing by Mechanical Methods", ASM International, (2003).

[4] G. Petzow, "Metallographic Etching", ASM, (1978). 